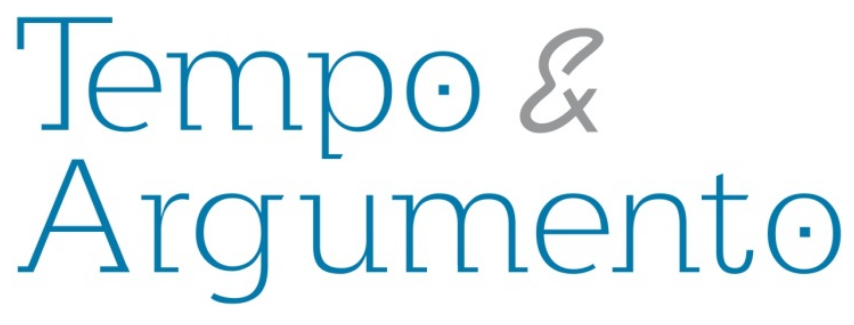

\title{
Universidade e repressão política: o acesso aos documentos da assessoria especial de segurança e informação da Universidade Federal do Espírito Santo (AESI/UFES)
}

\begin{abstract}
Resumo
O principal objetivo deste artigo é apresentar os problemas relacionados ao acesso aos documentos da Assessoria Especial de Segurança e Informação da Universidade Federal do Espírito Santo (AESI/UFES). Criada no âmbito do Ministério da Educação e Cultura e atuando no sistema coordenado pelo Serviço Nacional de Informação (SNI), a AESI/UFES funcionou entre 1971 e 1983 e teve como principal tarefa o monitoramento das atividades da comunidade universitária.
\end{abstract}

Palavras-chave: Ditadura Militar. Universidade Federal do Espirito Santo. AESI. ASI. Brasil - história.

\section{Pedro Ernesto Fagundes}

Professor do Departamento de

Arquivologia da Universidade Federal do Espírito Santo (UFES) e professor permanente do Programa de Pós-graduação em História (PPGHIS - UFES).

Doutor em História Social (UFRJ) pefagundes@uol.com.br

\section{Para citar este artigo:}

FAGUNDES, Pedro Ernesto. Universidade e repressão política: o acesso aos documentos da assessoria especial de segurança e informação da Universidade Federal do Espírito Santo (AESI/UFES). Revista Tempo e Argumento, Florianópolis, v. 5, n.10, jul./dez. 2013. p. 295 - 316.

DOI: $10.5965 / 2175180305102013295$

http://dx.doi.org/10.5965/2175180305102013295 


\title{
University and political
}

repression: access to documents

of the special safety and

information advice of the

Federal University of Espirito

Santo (AESI/UFES)

\begin{abstract}
The main purpose of this paper is to present the issues related to access to documents of the Assessoria Especial de Segurança e Informação da Universidade Federal do Espírito Santo (AESI/UFES). Established under the Ministry of Education and Culture and coordinated by the National Intelligence Service (Serviço Nacional de Inteligência - SNI), the AESI/UFES operated from 1971 to 1983 and its task of monitoring the activities of the university community.
\end{abstract}

Keywords: Military Dictatorship. Federal University of Espirito Santo. AESI. ASI. Brazil - history.

Os debates e discussões sobre o regime militar passaram a ocupar espaço destacado na historiografia brasileira nos últimos anos. A entrada em vigor da Lei $\mathrm{N}^{\circ}$ 12.527, de 18/11/2011 (chamada de Lei de Acesso a Informação: LAI), entre outros motivos, colaborou para o incremento de acervos sobre as atividades dos antigos órgãos de informação e segurança. Esta lei entrou em vigor em 16 mai. 2012. Apesar da existência ainda de entraves, representou para historiadores, estudantes, jornalistas, enfim, para 
inúmeras pessoas, a possibilidade de utilizarem documentos até então vetados à pesquisa.

Apesar dos avanços e de todos os esforços da equipe do Arquivo Nacional (AN), um importante conjunto documental ainda não foi encontrado - ou disponibilizado integralmente - à comunidade de pesquisadores: o acervo da Divisão de Segurança e Informação (DSI), do Ministério da Educação (MEC). ${ }^{1}$

Seja como for, após uma provocação positiva da Comissão Nacional da Verdade (Lei $\mathrm{n}^{\circ} 12.528$, de 18 nov. 2011), a busca por esse acervo motivou uma série de iniciativas interministérios, como a do Ministério da Justiça (MJ), que, através do Aviso n 1.069, de 4 jul. 2012, solicitou que todos os ministérios procedessem ao levantamento, à identificação e recolhimento - junto ao projeto "Memórias Reveladas”, do Arquivo Nacional (AN) - de documentos do período do regime militar que se encontrassem sob sua guarda.

Por tal motivo, em agosto de 2012, a Subsecretaria de Assuntos Administrativos do Ministério da Educação, através do Ofício-Circular n 11/2012/SAA/SE/MEC, remeteu a todos os reitores das universidades públicas, federais e estaduais, uma solicitação para que se realizasse um "Levantamento e Identificação dos documentos do Regime Militar a serem recolhidos ao Arquivo Nacional".

Para os objetivos do presente trabalho, esta é a informação mais importante. $\mathrm{Na}$ prática, tais ofícios solicitavam que as universidades deveriam buscar em seus arquivos documentos referentes à atuação dos chamados órgãos de informação que funcionaram durante o regime militar. Em resposta à demanda do MEC, em outubro de 2012, o Gabinete da Reitoria da Universidade Federal do Espírito Santo (UFES) solicitou ao seu Departamento de Arquivologia que realizasse um levantamento em todos os centros da universidade, com o objetivo encontrar tais documentos.

Buscando compreender melhor sua importância, antes de tratarmos das atividades de busca, coleta e descrição dos documentos da AESI/UFES, supõe-se ser útil

\footnotetext{
1 Sem esses documentos, parte considerável da rotina de vigilância e monitoramento no interior das universidades continuará sendo um vazio em relação à história do regime militar.
} 
contextualizar a criação e estruturação do aparato repressivo em nosso País no período pós-1964, principalmente sobre os órgãos que atuaram no interior das universidades.

Uma das primeiras medidas dos militares, depois que tomaram o Poder, foi estruturar a criação de um órgão voltado à vigilância, ao monitoramento e controle político e social. Assim, três meses depois do Golpe, surgiu o Serviço Nacional de Informação (SNI). O General Golbery do Couto e Silva foi o principal idealizador e primeiro militar a assumir a chefia do órgão. (FICO, 2001)

Inicialmente, as atividades do "serviço" estavam concentradas em levantar informações sobre indivíduos considerados "subversivos". Entretanto, apesar do surgimento de inúmeros órgãos ligados e subordinados ao SNI ao logo dos anos, pode-se afirmar que a escalada repressiva que marcou esse período contava com os seguintes fundamentos básicos: espionagem, censura e propaganda. Para os objetivos deste trabalho, concentraremos nossas tarefas na análise da estrutura de espionagem nas universidades brasileiras.

Outro fator importante foi a criação das chamadas Divisões de Segurança e Informação (DSI), que passaram a atuar no interior dos órgãos governamentais. Esses órgãos de segurança e informação foram implantados em inúmeros órgãos da estrutura estatal - ministérios civis, ministérios militares, autarquias, fundações e outros órgãos públicos.

Como citado acima, a abrangência e a estrutura do SNI - a partir da criação dos DSI's - possibilitou a atuação de seus agentes até mesmo no interior dos ministérios civis, sobretudo no interior das universidades:

Os jovens também foram perseguidos, sobretudo, o jovem universitário de classe média, tomado, de alguma maneira, pelo anseio de modificar o mundo: seriam subversivos, segundo a comunidade, ou inocentes úteis o que dava na mesma, quando se pensa, "apenas", no cotidiano da repressão. (FICO, 2001, p.67)

Dessa feita, podemos afirmar que o contexto dos anos finais da década de 1960 marcou o ponto culminante do processo de centralização da repressão política. Pode-se dizer que a criação de dezenas de órgãos de repressão foi resultado das pressões de 
setores das forças armadas, que viam a necessidade de "endurecer" o regime. Como observa o pesquisador Carlos Fico, o SNI iria passar por um adensamento de suas funções até se transformar num "monstro" a partir de 1969.

Existia uma permanente preocupação em controlar e vigiar as atividades de todos os setores da sociedade. Entre os setores mais atuantes estavam as Divisões de Segurança e Informação (DSI) do Ministério da Justiça e do Ministério da Educação, especialmente por lidar diretamente com os militantes estudantis e a intelectualidade, como veremos a seguir. (FICO, 2001, p.85)

Para assessorar as atividades de vigilância junto às DSI's foram criadas as chamadas Assessorias de Segurança e Informação (ASI) e as Assessorias Especiais de Segurança e Informação (AESI) em toda a estrutura estatal, civil ou militar. Em tese, o objetivo era monitorar possíveis casos de corrupção e a atuação de "comunistas" dentro de ministérios, repartições públicas e autarquias. (MOTTA, 2008a, p.44)

Assim, a estrutura repressiva ganhou musculatura administrativa e burocrática para atuar em todas as esferas da sociedade. Uma das justificativas utilizadas pelos militares para a criação de tais órgãos, entre eles o DSI/MEC, foram as massivas manifestações estudantis de 1968 - ano simbólico do movimento estudantil. Haja vista que, entre as prioridades do aparato repressivo, estava a vigilância do interior do campus.

É importante destacar que esse aparato foi efetivado a partir do Decreto $\mathrm{n}^{\circ}$ 60.940/1967. Inicialmente, tais órgãos estavam subordinados diretamente ao seu respectivo ministério. Contudo, a partir de maio de 1970, as DSI's passaram a ser subordinadas diretamente ao SNI, inclusive com dotação orçamentária própria. Nesse sentido, as AESI e ASI surgiram com a função de levantar informações setoriais. Segundo levantamento de dados do Arquivo Nacional (DF), existiram 249 desses órgãos voltados à vigilância e produção de informações. (ISHAQ, 2012, p.61)

Como destacamos anteriormente, entre os órgãos que atuavam nos ministérios civis, um dos maiores e mais atuantes foi a DSI/MEC. Sua tarefa principal era cuidar da vigilância e monitoramento das atividades da comunidade universitária, sobretudo do movimento estudantil, visto que as DSI's faziam parte do chamado "Sistema de 
Informação". Tais órgãos, no início da década de 1970, estavam diretamente subordinados ao SNI, ou seja, mesmo a vigilância nos órgãos civis passou a ser controlada diretamente pelas forças armadas. (FICO, 2001, p.79-80)

Assim, em outubro de 1970, efetivamente, através da "Diretriz Presidencial de Segurança Interna", a cúpula do regime começou a estruturar e planejar o combate mais ostensivo aos “inimigos da ordem”. (FICO, 2001, p.115-135). A principal inovação da 'Diretriz" foi a institucionalização do chamado Sistema Nacional de Segurança Interna (SISSEGIN). A partir de sua criação, as operações de repressão política foram centralizadas em nível nacional. Em outras palavras, as forças armadas iriam assumir o combate direto às "ameaças internas".

Neste sentido, foi criado o Destacamento de Operações de Informações-Centro de Operações de Ordem Interna (DOI-CODI). A ideia era centralizar e integrar a ação dos órgãos de repressão política. Dessa feita, os serviços de inteligência da Marinha (Cenimar), da Aeronáutica (CISA), a Polícia Federal (PF), as Polícias Militares (PM's) e, principalmente, os DOPS estaduais passariam a desenvolver seu trabalho de forma homogeneizada e sempre sob a coordenação do Exército.

Dessa forma, com a criação do SISSEGIN, forças armadas e polícia política unificaram esforços para enfrentar a ameaça "subversiva". De modo geral, o "sistema de informação e segurança" atuava em todos os setores e níveis. Entretanto, existiam alguns assuntos que ocupavam a pauta com mais frequência, que eram: a censura, os meios de comunicação, o clero, os estrangeiros e, tema dessa pesquisa, os professores e estudantes.

Em suma, a partir dessa época, passou a valer a lógica da suspenção em relação a todos e a tudo. O contado com os documentos dos antigos órgãos do aparelho repressivo, recentemente liberados para pesquisa, serviu para colocar por terra a falsa noção de que a repressão atuou de forma precisa e cirúrgica, ou seja, vigiou e monitorou apenas os indivíduos e grupos que aderiram à luta armada. A realidade passa longe disso.

O "olhar vigilante" do aparato repressivo - integrado e em sintonia com os órgãos locais - esteve presente em todos os setores da sociedade. Como dissemos, mesmo 
antes da criação das AESI/ASI, na prática, o "Sistema de Informação" trabalhava dentro das universidades, através da atuação do DSI/MEC.

Para auxiliar nessa tarefa e, sobretudo, explicitar a centralidade e a importância de “calar a universidade”, foi editada uma legislação que tinha uma finalidade básica: arrefecer o ímpeto dos estudantes e impor limites à liberdade de pensamento dos intelectuais. Dessa forma, evidenciando que a vigilância e monitoramento nas universidades se tornou uma das prioridades dos órgãos de segurança - além da criação do DSI/MEC -, a repressão aos integrantes do ME e aos professores passou a contar com um suporte jurídico específico: trata-se do Decreto $n^{\circ} 447$, de 28 fev. 1969.

O chamado Decreto 477, como ficou conhecido entre os estudantes, foi mais um instrumento típico do estado ditatorial brasileiro. Tanto que foi chamado pelos membros da comunidade universitária de "Al-5 do movimento estudantil". Seus seis artigos são mais um exemplo de como os militares utilizaram instrumentos jurídicos de exceção para limitar as manifestações da oposição.

Logo em seu artigo $1^{\circ}$, o decreto delimita os seus alvos: estudantes, professores e funcionários das instituições de ensino superior público ou particular. O artigo é complementado por seis incisos que, entre outras questões, tipificavam como atos "subversivos": organizar paralizações das atividades escolares ou participar delas; atentar como pessoas ou prédios das instituições; participar de desfiles ou passeatas sem autorização; confeccionar, imprimir, distribuir ou guardar material gráfico sem autorização; sequestrar ou manter em cárcere membros da instituição de ensino; utilizar o espaço da universidade "para fins de subversão" ou "praticar ato contrário à moral e à ordem pública".

As punições correspondentes eram apresentadas no $\S 1^{\circ}$, que eram, entre outras medidas, prévia demissão ou dispensa - no caso de professores ou funcionários -, com proibição de contratação por cinco anos, para voltar a exercer a mesma função. Os alunos enquadrados no Decreto Lei $n^{\circ} 477$ teriam sérios problemas em relação à sua vida acadêmica, pois poderiam ser desligados ou proibidos de fazer a matrícula durante um período de três anos. 
Outra medida, estabelecida no $\S 2^{\circ}$, determina que o "aluno infrator" perderia o direito a receber bolsa de estudos ou qualquer outro benefício concedido pelo governo durante cinco anos, ou seja, o tempo de duração da graduação. Demonstrando mais uma vez a paranoia do aparato repressivo com a "infiltração do Movimento Comunista Internacional" $(\mathrm{MCl})$ entre os jovens brasileiros, o $\S 3^{\circ}$ chegava a estabelecer a retirada de estudantes estrangeiros do País.

Os artigos $2^{\circ}$ e $3^{\circ}$, e seus respectivos parágrafos, tratavam dos mecanismos utilizados para apurar as infrações previstas: o processo sumário. Como dissemos, seguindo o ambiente jurídico da época, o Decreto Lei $\mathrm{N}^{\circ} 477$ estabelecia o prazo de 20 dias para apuração, instalação do inquerido e punição dos infratores. Em suma, num processo marcado pela celeridade, os prazos seriam limitados para que os indivíduos qualificados como infratores apresentassem os argumentos de defesa.

O Artigo $3^{\circ}$ e seus incisos 3 e 4 ratificam o caráter sumário de suas normas e procedimentos definidos:

Art. $3^{\circ} \mathrm{O}$ processo sumário será realizado por um funcionário ou empregado do estabelecimento de ensino, designado por seu dirigente, que procederá às diligências convenientes e citará o infrator para, no prazo de quarenta e oito horas, apresentar defesa. Se houver mais de um infrator o prazo será comum e de noventa e seis horas.

\section{$[\ldots]$}

$\S 3^{\circ}$ Apresentada a defesa, o encarregado do processo elaborará relatório dentro de quarenta e oito horas, especificamente a infração cometida, o autor e as razões de seu convencimento.

$\S 4^{\circ}$ Recebido o processo, o dirigente do estabelecimento proferirá decisão fundamentada, dentro de quarenta e oito horas [...].

Neste sentido, a leitura dos artigos, parágrafos e incisos do Decreto 477 permite conhecer de que forma o aparato de segurança utilizava as normas jurídicas como instrumento para "legalizar" a perseguição política, como se pode observar no $\S 1^{\circ}$, do mesmo Art. $3^{\circ}$, que determina a suspenção do emprego e função - no caso de professores e funcionários - até a data do julgamento.

Em relação aos estudantes, o decreto vai mais longe: proibia o discente de frequentar as aulas. As normas estabelecidas nos artigos $4^{\circ}, 5^{\circ}$ e $6^{\circ}$ tratam, 
respectivamente, do ressarcimento de possíveis danos patrimoniais causados pelo infrator e os prazos que o Ministério da Educação e Cultura tinha para agir, a partir da publicação do decreto.

Assim, pode-se afirmar que a escalada repressiva nas universidades contou com uma diversificada e ampla estrutura de repressão. O primeiro passo foi a criação do DSI/MEC, em 1968. Em seguida, em 1969, entrou em vigor o Decreto 477. É possível dizer que o ponto culminante da estruturação desse aparato ocorreu em 1971, pois, foi essa a data de criação de um mecanismo específico para monitorar, vigiar e, sobretudo, levantar informações. Esses órgãos que atuaram no interior de dezenas de universidades brasileiras ficaram conhecidos como Assessorias Especiais de Segurança e Informação (AESI).

No geral, as AESI deveriam atuar nas universidades públicas - federais e estaduais com o levantamento de informações no interior da comunidade universitária. Em outras palavras, o surgimento dessas assessorias teria como finalidade identificar e monitorar os chamados "elementos subversivos", dentro de um espaço considerado crítico: o campus.

No âmbito das Universidades, as AESI foram criadas a partir de janeiro de 1971, após o Ministério da Educação e Cultura ter aprovado seu Plano Setorial de Informação [...]. Poucos dias após a aprovação do Plano, a DSI do MEC mandou ofício circular às universidades acompanhada da documentação relativa à criação das $\mathrm{AESI}$, em que recomendava a nomeação do chefe responsável em prazo de 10 dias. (MOTTA, 2008b, p.35)

A Portaria $\mathrm{n}^{\circ}$ 10, BSB, de 13 de janeiro de 1971, marcou a criação das primeiras AESI/ASI. ${ }^{2}$ Como foi dito, a partir do surgimento desse mecanismo específico, o aparato repressivo adquiriu um importante instrumento para a coleta de informações dentro das universidades. As prioridades desses órgãos eram: coleta de informações sobre atividades das lideranças estudantis e professores, controle da nomeação para cargos, viagens de docentes e discentes para eventos científicos, censura de livros, proibição de manifestações, confisco de material considerado "subversivo", entre outras. Assim, as

\footnotetext{
${ }^{2}$ Como observa Rodrigo Patto Sá Motta, era comum encontrar o uso das duas siglas. Contudo, no período final da ditadura militar, a denominação mais comumente utilizada era ASI.
} 
ASI/AESI atuaram como mais um mecanismo de controle e vigilância da chamada “Comunidade de Informação".

A criação das ASI/AESI, como destaca em seus trabalhos o pesquisador Rodrigo Patto Sá Motta (UFMG), representou uma violência cotidiana no interior das universidades. Outro aspecto importante de se destacar - além da ameaça de prisão, tortura, expulsão ou morte - é que essa estrutura de repressão significou a ação permanente de um instrumento de intimidação e constante ameaça para discentes, professores e funcionários.

Representou, também, o estabelecimento de práticas rotineiras de invasão da intimidade de cidadãos não engajados em movimentos de resistência armada. Outro aspecto foi o estabelecimento de um ambiente de suspeita permanente em relação aos denunciados e aos delatores. Dessa forma, a violência, a suspensão, a desconfiança, o sigilo e o silêncio passaram a compor o cotidiano das universidades. O emprego dessa tática serviu para - momentaneamente - para silenciar, desarticular e desorganizar as entidades estudantis.

Segundo dados do Arquivo Nacional, existiram órgãos de informação em quase 36 universidades públicas (estaduais e federais). ${ }^{3}$ Como foi dito, inicialmente, em algumas universidades - na UFES, por exemplo, até meados de 1975 - essas estruturas ficaram conhecidas como Assessoria Especial de Segurança e Informação (AESI). Posteriormente, adotaram em seus documentos oficiais a nomenclatura de Assessoria Especial de Segurança (ASI).

Voltando ao trabalho de pesquisa sobre o acervo documental da AESI/UFES, os primeiros contatos com documentos desse órgão ocorrem durante a pesquisa documental que realizamos sobre a trajetória da Delegacia de Ordem Política e Social do Estado do Espírito Santo (DOPS/ES), acervo custodiado no Arquivo Público (APES). Desde 2009, coordenamos uma pesquisa sobre a repressão política no Espírito Santo, durante a

\footnotetext{
${ }^{3}$ Em um de seus artigos que tratam do tema, o historiador Rodrigo Patto Sá Motta (UFMG) cita a existência de ASI em 33 universidades. Ver em: MOTTA2008b p. 38.
} 
qual, particularmente na "Série Movimento Educacional", foram encontrados em torno de 35 documentos específicos da ASI/UFES (com papel timbrado, carimbo e assinatura de funcionários).

Outra importante descoberta ocorreu durante o período de pesquisa que realizamos, em outubro de 2012, no acervo do SNI, custodiado no Arquivo Nacional, em Brasília. Nessa oportunidade, foram pesquisados os acervos do SNI e da Polícia Federal, relativos, principalmente, ao estado do Espírito Santo. Durante a estadia no AN, verificamos que a UFES (estudantes e professores) foi um locus privilegiado de atuação dos órgãos de repressão. Contudo, ainda existia uma grande interrogação: existiriam documentos da AESI/UFES nos arquivos da própria universidade?

Nesse sentido, nossa primeira atividade foi buscar informações atualizadas sobre o paradeiro dos documentos do antigo órgão de informação. É preciso dizer que as primeiras investigações ocorreram ainda durante os trabalhos do projeto anterior sobre os arquivos da repressão no ES, o primeiro deles em 2011, por uma aluna de iniciação científica, que atuou sob nossa coordenação.

Naquela época, os resultados foram desanimadores, pois as informações indicavam que o acervo teria sido destruído num incêndio que atingiu o arquivo central da UFES em 1999; ou o antigo chefe da AESI/UFES, após sua aposentadoria, que teria levado os documentos para sua residência; ou os documentos da AESI/UFES, que estariam espalhados de forma desorganizada por todos os centros da UFES; ou que, com o fim do órgão em 1983, seu acervo fora recolhido para o arquivo da Delegacia do MEC e, posteriormente, enviado para Brasília.

Contudo, como apresentamos anteriormente, a partir da provocação da Comissão Nacional da Verdade, da solicitação de dois Ministérios (MEC e MJ) e da Reitoria da UFES, a busca pelos "documentos perdidos" iria adquirir caráter oficial. Tanto que, durante o período letivo 2012/2, foi ofertada uma disciplina no Departamento de Arquivologia (coordenada em parceria com a profa Margarete Farias de Moraes), que reuniu 20 discentes na tarefa de procurar esse conjunto documental. 
Poucos dias depois do início dos trabalhos, em novembro de 2012, os primeiros documentos específicos foram encontrados junto ao arquivo do Departamento de Arte/UFES. São em torno de 350, que reúnem memorandos, ofícios, pedidos de informação, relação de livros censurados, solicitações de informação sobre o Diretório Acadêmico, entre outros.

O primeiro contato com esses documentos, encontrados no interior da universidade, serviu de estímulo para o aprofundamento das pesquisas nos outros centros da instituição. Assim, foram realizadas buscas em inúmeros locais da Ufes, tais como banheiros desativados, que haviam sido convertidos em "arquivos" no prédio da Reitoria, em almoxarifados, embaixo de escadas e em salas desativadas no ginásio de esportes do Centro de Educação Física.

Toda essa busca permitiu que, até outubro de 2013, fossem recuperados 1.200 páginas de documentos em quase todos os centros da universidade. No momento, esse conjunto documental está em processo de tratamento e descrição, tarefa realizada por discentes dos departamentos de Arquivologia e História, sob a orientação da Comissão da Verdade da UFES.

Contudo, as pesquisas já realizadas nos acervo do DOPS/ES (Apees) e do SNI (AN), somadas aos primeiros contatos com o conjunto documental da AESI/UFES, possibilitam algumas ponderações sobre a atuação dos órgãos de informação no interior do campus. No momento, sabe-se que a AESI/UFES iniciou seus trabalhos entre julho e agosto de 1971, haja vista que o documento mais antigo até agora encontrado , é o oficio $\mathrm{n}^{\circ}$ 02/71, AESI/UFES, que data de 17 de agosto de 1971, portanto, durante a gestão do ex-reitor Máximo Borgo Filho (15 jul. 1971 a 16 jul. 1975).

Desse modo, a partir das pesquisas nos acervos dos órgãos de repressão citados DOPS/ES, SNI e AESI/UFES -, podemos chegar à seguinte constatação: durante o período da Ditadura Militar (1964-1985) ocorreram quatro grandes ondas repressivas no interior da UFES. A constatação dessas quatro ondas não significa que a repressão tenha ocorrido apenas durante esses períodos, pois, em nosso entendimento, houve uma rotina de vigilância ao longo da Ditadura Militar. 
Essas ondas repressivas envolveram estudantes, professores e funcionários. Por ondas repressivas entendemos os momentos de maior produção de documentos, vigilância e outras ações que afetaram o cotidiano da instituição, como: proibição ou suspensão de entidades estudantis, abertura de inquéritos contra professores e funcionários, confisco de material e documentos, prisões, etc.

Obviamente, a primeira onda repressiva ocorreu nos primeiros momentos depois do Golpe, entre abril e maio de 1964. O novo quadro político abriu caminho para as investigações sumárias e diversos inquéritos policiais militares (IPM's) ${ }^{4}$ que atingiram, principalmente, militantes estudantis e servidores públicos (civis e militares) identificados com o governo de João Goulart.

Portanto, as universidades brasileiras foram palco de uma série de IPM's, que pretendiam realizar um levantamento de possíveis casos de subversão entre os estudantes, professores e funcionários. Na UFES, esse ambiente foi determinante para o afastamento do reitor Manoel Xavier Paes Barreto Filho (18 jun. 1963 a 14 abr.1964). ${ }^{5}$

Com o golpe Civil Militar de 1964, as entidades estudantis passaram a ser alvo de uma série de represálias, em especial a União Nacional dos Estudantes (UNE), diretamente afetada nesse primeiro momento. Como afirma João Roberto Martins Filho, apesar de ter sido criada em 1937, a UNE tornou-se uma entidade de massas apenas no início da década de 1960. A atuação da entidade em defesa das "Reformas de Base" foi determinante para as perseguições pós-golpe. (MARTINS FILHO, 1987, p.58-65)

Logo nos primeiros dias do novo regime, foram efetuadas prisões em todo o território nacional e entidades estudantis e centros acadêmicos foram fechados. $\mathrm{O}$ evento mais emblemático foi o incêndio da sede da UNE, no Rio de Janeiro, em abril de 1964. Nesse mesmo sentido, passeatas, assembleias, panfletos, enfim, qualquer tipo de manifestação estudantil passou a ser suspeito de subversão à ordem política e social.

\footnotetext{
4 É possível encontrar outras denominações para esse tipo de procedimento, tais como: inquéritos administrativos ou processos administrativos.

${ }^{5}$ Para mais informações, ver: BORGO, 1995
} 
Nas universidades, foram instaurados inquéritos policias militares (IPM's) e inquéritos administrativos que indiciaram funcionários e, principalmente, estudantes. Inúmeros reitores foram afastados de seus postos; professores foram demitidos e estudantes, expulsos. Como foi dito, na UFES, o período pós-golpe foi marcado pelo afastamento do reitor, pela detenção de dezenas de estudantes e pela abertura de inquéritos administrativos em todos os centros de ensino da universidade.

O golpe abriu caminho para o endurecimento da repressão aos estudantes. A fase entre 1964 e 1966 teve como marca principal a repressão do regime militar contra o movimento estudantil. Tanto que, em novembro de 1964, a UNE foi fechada por conta da Lei $n^{\circ} 4.464$, conhecida como Lei Suplicy - o autor da proposta foi o então ministro da Educação Flavio Suplicy de Lacerda. Outro instrumento de repressão criado nessa época foi o Decreto-Lei $n^{\circ} 228 / 1967$, que, entre outras medidas, ampliava o poder de intervenção do nas entidades estudantis.

Paralelamente à escalada da repressão política, o governo militar atuou no sentido de direcionar sua política educacional para afirmar seu projeto de modernização autoritária. (MARTINS, FILHO, 1987, p.187) Neste sentido, era fundamental "sanar" a universidade dos "elementos perigosos" e, ao mesmo tempo, preparar novos dirigentes, intelectuais e a mão-de-obra especializada afinados com as diretrizes do estado ditatorial.

Entre esse conjunto de iniciativas, uma das mais destacadas foi o acordo entre o Ministério da Educação e Cultura com um organismo vinculado ao Departamento de Estado norte-americano chamado United States Agency for Internacional. Na verdade, o chamado Acordo MEC/USAID, foi uma das iniciativas que compunham um projeto muito mais amplo que ficou conhecido como "Reforma Universitária". ${ }^{6}$

Passada essa onda repressiva dos anos iniciais pós-golpe, o movimento estudantil foi se rearticulando em nível nacional. No Espírito Santo, esses anos tiveram como principais fatores de mobilização dos estudantes as reivindicações por mais vagas nos cursos superiores - a questão dos "excedentes" - e pela construção de mais restaurantes universitários.

\footnotetext{
${ }^{6}$ Para saber mais, ver em: MARTINS FILHO, 1987.
} 
A segunda onda repressiva na UFES ocorreu exatamente entre 1968 e 1969, como foi dito, período marcado por manifestações estudantis em plano internacional, conhecidas como "mística de 68". Durante aquele ano, o mês de março foi marcante para o ME brasileiro, especialmente o dia 28. Essa foi a data da trágica morte do estudante Edson Luis, acontecida em um conflito entre agentes da repressão e estudantes, nas ruas do Rio de Janeiro. As semanas posteriores foram pontuadas por passeatas, protestos e enfrentamentos em diversas cidades brasileiras, inclusive em Vitória, capital do Espírito Santo.

O DCE das UFES - sob a presidência de Cesar Ronald Pereira Gomes - convocou uma série de manifestações, durante a primeira semana de abril de 1968, para protestar contra o assassinato de Edson Luis. Segundo a imprensa capixaba - edições dos dias 3, 4, 5 e 6 do jornal A Gazeta -, milhares de estudantes protagonizaram uma série de manifestações, com destaque para uma missa de $7^{\circ}$ dia realizada na catedral metropolitana, no centro da capital. Nessa noite, ocorreram confrontos entre os estudantes e a polícia.

Nesse mesmo ano, em outubro, aconteceu o XXX Congresso da UNE - organizado de forma clandestina no sítio Murundu, na zona rural de Ibiúna (SP). No dia 12 desse mês, integrantes das forças de repressão invadiram o sítio e, na ação, as principais lideranças no movimento estudantil brasileiro acabaram sendo presas, entre elas estudantes capixabas. Os 13 estudantes do Espírito Santo detidos em Ibiúna são: Agis Wilson Macedo, Areovaldo Costa Oliveira, Cesar Ronald Pereira Gomes, Domingos de Freitas Filho, Estela Maria Ourique da Silva, JosÁ Antonio Gorza Pignaton, Jose Honório Machado, Luis Claudio Nogueira Muniz, Iran Caetano, Jussara Lins Martins, Marcelo de Almeida Santos Neves, Marlene do Amaral Simonetti e Ricardo Luiz Carvalho Gotardi. ${ }^{7}$

Deu-se início a uma ampla operação de repressão, que culminou na completa desarticulação do movimento estudantil brasileiro. Nesse período, é possível observar nos documentos pesquisados que era constante a troca de ofícios entre a Reitoria da

\footnotetext{
${ }^{7}$ Dossiê Operação Ibiúna. Arquivo Público do Estado de São Paulo.
} 
UFES, durante a gestão de Alaôr Queiroz de Araújo (3 dez. 1965 a 16 jun. 1971), e os representantes da DSI/MEC e da agência do SNI, na capital capixaba.

Confirmando a tendência de endurecimento da ditadura contra o movimento estudantil, no início de 1969 ocorreu a invasão da sede e posterior fechamento do DCE da UFES. A entidade máxima dos estudantes ficaria sob intervenção e proibida de realizar eleições até 1978. A primeira metade da década de 1970 foi marcada pela repressão que levou à desarticulação das entidades estudantis no Brasil.

A posse do novo general/presidente Emilio Garrastazu Médici (1970-1974) marcou o início dos chamados "anos de chumbo", por causa endurecimento da repressão contra os opositores do regime. Assim, para os estudantes as manifestações de rua, principal instrumento de mobilização até então, por razões obvias deixou de ser a estratégia mais utilizada. Como veremos a seguir, em face dessa nova realidade os estudantes desenvolveram novas estratégias de militância.

O cenário nas universidades brasileiras nos anos iniciais da década de 1970 foi marcado por uma repressão política cotidiana. As pesquisas nos acervos dos antigos órgãos permite observar que houve uma massiva ação interna no sentido de confiscar, vigiar e monitorar as atividades nas universidades. Por conta desse ambiente, ocupar as ruas passou a representar risco de morte, prisão, expulsão ou demissão.

A fase que marcou a implantação e pleno funcionamento da AESI/UFES coincide com a terceira onda repressiva nessa universidade. Seu ponto máximo ocorreu entre dezembro de 1972 e março de 1973, época marcada por uma série de prisões e perseguições de professores e estudantes na instituição, sobretudo aqueles que militavam no Partido Comunista do Brasil (PCdoB). Foi aberto um inquérito policial militar (IPM) que arrolou 33 pessoas suspeitas de militarem no PCdoB. A maioria dos arrolados no IPM, ou seja, 18 pessoas, tinha ligação direta com a UFES. No total, eram 17 discentes oito do curso de Medicina - e um professor (Vitor Buaiz, também do Departamento de Medicina). ${ }^{8}$

\footnotetext{
${ }^{8}$ BR.ES.APEES.DES.O.MP.6 CX. 16. Arquivo Público do Estado do Espírito Santo.
} 
Entre os estudantes estavam: Marcelo Amorim Neto (Medicina); Gustavo Ferreira do Vale Neto (Medicina); Sebastião Lima Nascimento (Medicina); Elizabeth Santos Madeira (Medicina); Maria Magdalena Frechiani (Medicina); Luzimar Nogueira Dias (Medicina); Guilherme Lara Leite (Medicina); Marcus Lira Brandão (Medicina); Luiz Carlos Garcia Genelhu (Medicina); Iran Caetano (Medicina); Adriano Sisternas (Engenharia); Mirian Azevedo de Almeida Leitão (CEG); Angela Milanez Caetano (CEG); Maria Gilma Erlacher (Direito); Maria Auxiliadora Ferreira Gama; Jorge Luiz de Souza (Economia); José Willian Sarandy (Direito).

Através dos documentos do SNI pesquisados no AN e no DOPS/ES, é possível constatar a presença de integrantes do Destacamento de Operações de Informações Centro de Operações de Defesa Interna (DOI-CODI), do $1^{\circ}$ Exército (Rio de Janeiro), à frente das investigações e da repressão que aconteceram no Espírito Santo, sobretudo na UFES, em 1973.

Em nível nacional, apesar do adensamento da repressão durante os chamados "anos de chumbo", diversos grupos identificados com a luta pela redemocratização do País começaram a rearticular suas ações. Entre esses grupos, podemos citar: intelectuais, artistas, representantes do "novo sindicalismo" e militantes da chamada "ala progressista" da Igreja católica. Foi nesse cenário que o movimento estudantil retomou suas ações.

Os militantes estudantis ocuparam posição de destaque; contudo, adotando uma nova estratégia. Assim, por exemplo, as manifestações de rua - por conta do endurecimento da repressão - deixaram de ser a estratégia mais utilizada e em seu lugar as atividades do ME concentraram suas atividades no interior do campus. Como veremos a seguir, em virtude dessa nova realidade, os estudantes desenvolveram novas estratégias de militância.

Um dos pontos marcantes dessa retomada das atividades de rua ocorreu em março de 1973, durante as mobilizações pacíficas de luto e protesto pela morte de Alexandre Vannucchi Leme - estudante da USP morto enquanto estava sob custódia do DOI-CODI/SP. Em resposta, os estudantes dos mais diversos cursos mobilizaram e 
organizaram uma missa na catedral da Sé que, apesar do forte esquema de repressão, reuniu aproximadamente três mil pessoas. Essa liturgia - celebrada pessoalmente por Dom Paulo Evaristo Arns - serviu para aproximar setores como Igreja Católica, Ordem dos Advogados do Brasil (OAB), setores do Movimento Democrático Brasileiro (MDB) e da Associação Brasileira de Imprensa (AIB). (CANCIAN, 2010, p. 40-43)

Mesmo que internamente, nos campi, entre os anos de 1974 e 1976, os militantes estudantis deram continuidade às suas atividades. Como destaca Maria Paula Araújo, por causa da repressão foi necessário elaborar táticas alternativas de atuação. Essa nova conjuntura permitiu o surgimento de atividades, tais como encontros acadêmicos de áreas, atividades culturais (cinema, teatro, música, etc.) e imprensa alternativa. (ARAUJO, 2007, p. 209-216)

Mesmo com toda a vigilância e repressão, como foi dito, em seu conjunto essas atividades serviram para reaproximar os estudantes das discussões, debates, manifestações, enfim, da rotina típica do ME. Entre os estudantes, essa nova realidade possibilitou a articulação de inúmeras tendências.(ARAUJO, 2007, p.217)

De fato, essas "novas tendências" seriam a fórmula encontrada para que os partidos e organizações - ainda na clandestinidade - pudessem atuar no interior do campus. O itinerário político, as características, os componentes e principais propostas das tendências estudantis servem como pano de fundo das principais mobilizações em torno da reorganização das entidades, principalmente na Universidade de São Paulo (USP). Isso porque a reorganização DCE Livre da USP, em 1975, foi um acontecimento fundamental para a articulação do movimento estudantil em nível nacional.

A partir de 1977, o movimento realiza, em nível nacional, uma série de atividades que ficaram conhecidas como Dia Nacional de Luta pelas Liberdades Democráticas. Tantas mobilizações tiveram como principal palavra de ordem as chamadas "liberdades democráticas", com destaque para a bandeira da anistia política.

Nesse ano ainda, outros acontecimentos importantes foram as mobilizações em torno da reorganização da UNE, sobretudo os esforços nas articulações em torno dos chamados Encontros Nacionais de Estudantes (ENE's). Inicialmente marcado para 
acontecer em Belo Horizonte, o evento foi adiado, principalmente, por causa do forte esquema de repressão montado na capital mineira. (RAMAGNOLI, 1979, p. 29)

Mostrando disposição de rearticular o ME em nível nacional, foi programado um novo III ENE, agora com sede na PUC/SP. Esse evento teve dois momentos distintos: por um lado, representou uma vitória com a criação da comissão pró-UNE. Entretanto, por outro lado, a invasão significou um dos episódios de maior truculência com destruição de parte do campus e prisão de centenas de estudantes. ${ }^{9}$

Em 1978, apesar do clima político marcado pela repressão e monitoramento, os militantes estudantis conseguiram organizar/reorganizar inúmeras entidades gerais, com destaque para as UEEs (União Estadual de Estudantes) e os DCEs (Diretório Central de Estudantes) nos mais diversos estados. O marco simbólico dessas mobilizações foi o Congresso de Refundação da UNE, em maio de 1979, na cidade de Salvador-BA. (MULLER, 2010)

A quarta onda repressiva na UFES teve início exatamente na época da retomada das atividades do ME em nível nacional, a partir de 1977, com as mobilizações que pretendiam reorganizar a União Nacional dos Estudantes (UNE). Paralelamente, os estudantes da UFES recomeçaram suas mobilizações a partir de atividades convocadas pelos diretórios acadêmicos do Centro de Ciências Jurídicas e Econômicas (DACCJE) e do Centro de Biomédicas (DACBM). (FAGUNDES, 2012, p.29)

Como é possível verificar nos arquivos pesquisados, essas mobilizações concentraram os esforços de agentes dos mais variados órgãos de repressão, entre eles: SNI, CISA, CENIMAR, DOPS/ES e, obviamente, AESI/UFES. Em novembro de 1978, depois de meses de intensos debates, aconteceu a eleição para escolha da nova diretoria do DCE da UFES. Os agentes da repressão acompanharam com especial atenção todas as atividades ligadas à reorganização da entidade máxima dos estudantes da UFES. Inúmeros relatórios foram produzidos e difundidos, monitorando as cinco chapas que concorreram - Construção, Ação Popular Estudantil, Retomada, Liberdade e Anistia, e Frente de Libertação Estudantil.

\footnotetext{
${ }^{9}$ Para saber mais, ver em: CANCIAN, 2010.
} 
A partir da reorganização do DCE/UFES, a vigilância de assembleias, passeatas, reuniões, participação dos dirigentes na campanha pela Anistia, eleições. O confisco de material de propaganda das tendências do movimento estudantil tornou-se tarefa cotidiana no interior do campus. Em nível nacional, parte das AESI/ASI deixou de funcionar a partir de 1979. Algumas, como a da UFES, continuou em funcionamento depois dessa data.

A AESI/UFES funcionou, com essa nomenclatura até 1983. Nesse ano, seus documentos e funcionários teriam sido transferidos para a Assessoria Especial de Segurança da Delegacia do Ministério da Educação e Cultura - ASI/DEMEC/ES. Contudo, em agosto de 1986, o MEC editou portaria ( $n^{\circ} 576$, em 5 ago.1986), extinguindo as ASI ainda existentes nas universidades brasileiras. (MOTTA, 2008 ${ }^{a}$, p.58)

O objetivo do presente texto foi apresentar um primeiro balanço sobre itinerário e percalços que marcaram e ainda marcam a busca por essas fontes consideradas sensíveis. Também foi nossa intenção destacar o potencial de pesquisa que representa o encontro da comunidade universitária com esse acervo, até há pouco inédito, ou seja, sublinhar que a possibilidade de acesso aos documentos da AESI/UFES poderá contribuir para preencher importantes páginas da história da repressão política no País.

Podemos dizer que o presente contato com essas fontes abre um amplo leque de possibilidades para o aprofundamento da democracia. Entre elas, por exemplo, romper com a cultura do silêncio e construir a cultura do acesso à informação. A descoberta desses “documentos perdidos" representa uma oportunidade única para a comunidade universitária reencontrar, contar, enfim, conhecer episódios que ocorreram na universidade durante os "anos de chumbo".

Oportunidade, sobretudo, de conhecer a respeito do funcionamento desse órgão de informação que atuou na UFES. Como dissemos anteriormente, a criação das AESI representou uma violência cotidiana no interior das universidades. Na prática, essa estrutura de repressão significou a ação de um instrumento de intimidação e ameaça permanente para discentes, professores e funcionários. 
Assim, além da importante tarefa de elucidar fatos ligados às atividades das forças oficiais de repressão, nossa meta foi a de realizar uma reflexão sobre o estágio atual dos trabalhos que utilizam os arquivos repressivos como objeto de pesquisa. Dessa feita, as pesquisas constituem uma ferramenta fundamental no sentido de evitar o esquecimento de uma época marcada por lutas e repressões políticas.

Mesmo não estando entre nossas metas iniciais, a recuperação de parte do acervo da AESI/UFES foi um dos fatores fundamentais que incentivaram a instalação da Comissão da Verdade na UFES - que oficialmente iniciou suas atividades a partir de março de 2013-, uma das primeiras dentro de uma instituição de ensino no Brasil.

Como dissemos ao longo do texto, reiteramos nossa expectativa de que a descoberta desse conjunto documental, somado ao trabalho da Comissão da Verdade da Ufes, colabore na recuperação e entendimento de episódios da história na universidade durante a Ditadura Militar.

\section{Referências}

ARAUJO, Maria Paula Nascimento. Memórias estudantis: da fundação da UNE aos nossos dias. Rio de Janeiro: Relume Dumare: Fundação Roberto Marinho, 2007.

BORGO, Ivanir Antonio. UFES: 40 anos de história. Vitória. EdUFES/Secretaria de Produção e Difusão Cultural, 1995.

CANCIAN, Renato. Movimento estudantil e repressão política: o ato público na Pontifícia Universidade Católica de São Paulo (1977) e o destino de uma geração de estudantes. São Carlos: Editora da Universidade Federal de São Carlos (EdUFSCar), 2010.

FAGUNDES, Pedro Ernesto. Memórias silenciadas: catalogo seletivo dos panfletos, cartazes e publicações confiscadas pela Delegacia de Ordem Política e Social do Estado do Espírito Santo - DOPS/ES (1930-1985). 1. ed. Vitória - ES: GM Editora, 2012.

FICO, Carlos. Como eles agiam. os subterrâneos da ditadura militar: espionagem e polícia política. Rio de Janeiro: Record, 2001.

ISHAQ, Vivian; FRANCO, Pablo Endrico; SOUSA, Teresa Eleutério de. A escrita da repressão e da subversão. Rio de Janeiro: Arquivo Nacional, 2012. 
MARTINS FILHO, João Roberto. O movimento estudantil e a ditadura militar: 1964-1968. Campinas: Papirus, 1987.

MOTTA, Rodrigo Patto Sá . Incômoda memória: os arquivos das ASI universitárias. Acervo. Rio de Janeiro, v. 16, 2008a. p. 32-50.

MOTTA, Rodrigo Patto Sá. Os olhos do regime militar nos campi:. as assessorias de segurança e informações das universidades. Topoi. Rio de Janeiro, v. 9, 2008.b p. 30-67.

MULLER, Angélica. A resistência do movimento estudantil brasileiro contra o regime ditatorial e o retorno da UNE á cena publica (1969-1979). 2010.Tese ( Doutorado) Universidade de São Paulo (USP) - São Paulo.2010

RAMAGNOLI, Luiz Henrique; GONÇALVES, Tânia. A volta da UNE: de Ibiúna a Salvador. História imediata, n.5. São Paulo: Alfa-Ômega, 1979. 